\title{
The Bone Morphogenetic Protein Antagonist Gremlin Promotes Vascular Smooth Muscle Cell Apoptosis
}

\author{
Thiago Trovati Maciel ${ }^{a, b}$ Rosilene Santos Melo ${ }^{b}$ Alexandre Holthausen Campos ${ }^{a}$

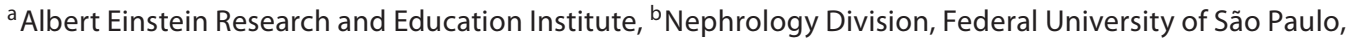 \\ São Paulo, Brazil
}

\section{Key Words}

Apoptosis - Bone morphogenetic proteins - Gremlin •

Vascular injury $\cdot$ Vascular smooth muscle cells

\begin{abstract}
Background: Previous studies from our laboratory demonstrated that gremlin significantly increases vascular smooth muscle cell (VSMC) proliferation and migration. The present study investigates gremlin expression in the initial stages of rat carotid balloon injury and its effects on VSMC apoptosis. Methods: Gremlin mRNA expression was evaluated in rat carotids and cultured VSMCs by quantitative PCR. Apoptosis was analyzed in A7r5 cells and rabbit primary VSMCs following gremlin gene overexpression or silencing by chromatin morphology and caspase-3 activity. Results: Vascular injury promoted a significant decrease in gremlin mRNA levels. In addition, platelet-derived growth factor, angiotensin II and transforming growth factor (TGF)- $\beta 1$ promoted coordinated regulation of gremlin and bone morphogenetic protein (BMP)-4 expression in opposite directions according to the confluence status of VSMC culture. In A7r5 cells, gremlin overexpression was able to increase apoptosis, as demonstrated by chromatin morphology and caspase-3 activity, while BMP administration promoted opposite effects. Finally, in agreement with our results, gremlin gene silencing effectively suppressed apoptosis in A7r5 cells and rabbit VSMCs. Conclusion: Gremlin is regulated by growth factors
\end{abstract}

and vascular injury and is involved in modulation of VSMC apoptosis. Modifications of gremlin expression during vascular injury may contribute to the apoptosis resistance of VSMCs.

Copyright $\odot 2009$ S. Karger AG, Basel

\section{Introduction}

Carotid artery balloon injury promotes vascular smooth muscle cell (VSMC) apoptosis due to mechanical stress, culminating in loss of vascular cellularity [1]. In addition to cell migration and proliferation $[2,3]$, VSMC apoptosis is essential in the development of neointima [4-6]. Recent studies suggest that mechanisms involved in cell proliferation are also able to modulate cell death [4]. In addition, expression of growth factors in the vessel wall allows VSMC to accumulate due to progression of the cell cycle and apoptosis resistance $[4,7]$.

Recent studies have focused on inhibitors of cell proliferation, such as bone morphogenetic proteins (BMPs), which are able to block VSMC proliferation in vitro and in vivo [8]. BMPs are cysteine knot proteins that belong to the transforming growth factor (TGF)- $\beta$ superfamily [9] and have been associated with atherosclerosis [10] and vascular calcification [11]. Signal transduction of BMP family members depends on smad phosphorylation and nuclear translocation of active complexes [12] and is 
modulated by temporal and tissue-specific expression of extracellular BMP antagonists [13], including gremlin [13]. Gremlin binds to BMP-2, -4 and -7 , blocking ligandreceptor interaction [14]. Our laboratory demonstrated that gremlin is constitutively expressed in VSMCs and is significantly regulated by classic growth factors related to the development of vascular injury [15]. In vivo, gremlin expression levels were increased in later stages (4 weeks) of carotid artery injury, when neointima was already established. Our in vitro studies also demonstrated that gremlin induces cell proliferation and migration, contributing to neointimal development. However, the role of gremlin in VSMC apoptosis is unknown.

It is postulated that the balance between BMP and gremlin tissue expression could predict the BMP pathway signaling level and cell fate. The present study evaluated gremlin expression at earlier stages (1-7 days) of vascular injury, when marked apoptosis occurs. We verified that VSMC apoptosis is increased by gremlin and reduced by BMPs. In agreement with our hypothesis, gremlin RNA silencing significantly reduced VSMC death. In vivo, gremlin mRNA levels were markedly reduced $1-3$ days following vessel injury, which potentially contributes to the development of the VSMC apoptosis resistance observed in this model. Taken together, the results presented here emphasize the importance of the modulation of the BMP pathway in the pathophysiology of vascular injury.

\section{Methods}

\section{Rat Carotid Artery Balloon Injury}

Male Sprague-Dawley rats (300-400 g) were submitted to balloon injury according to previously described methods [16]. A 2Fr Fogarty catheter was used to induce vascular injury. Rats were anesthetized with an intraperitoneal injection of xylazine $(5 \mathrm{mg} /$ $\mathrm{kg}$ of body weight) and ketamine hydrochloride $(90 \mathrm{mg} / \mathrm{kg}$ of body weight), and the catheter was introduced into the left common carotid via the external carotid artery. No adverse neurological or vascular effects were observed in any animal undergoing the procedure. All procedures were approved by the local Ethics Committee. After 1, 3 or 7 days, injured carotid arteries and their contralateral controls were removed for RNA analysis.

\section{Cell Culture}

Primary aortic smooth muscle cells were obtained from explant cultures of aortic tissue from adult Sprague-Dawley rats and from New Zealand rabbits (original samples kindly donated by Dr. Chester Sacramento, InCor, São Paulo, Brazil). Clonal rat embryonic VSMCs (A7r5) were obtained from ATCC. Aortic smooth muscle cells were treated with angiotensin (Ang) II (300 nmol/l; Sigma-Aldrich, St. Louis, Mo., USA), TGF- $\beta 1$ ( 5 ng/ml; Sigma-
Aldrich) or platelet-derived growth factor (PDGF; $2 \mathrm{ng} / \mathrm{ml}$; Sigma-Aldrich) for gremlin expression analysis. Cells stably overexpressing gremlin (gremlin-A7r5) and their controls (empty-A7r5; pMEX and pMEX-F5 plasmids were a kind gift from Dr. Donald Blair, National Cancer Institute, Frederick, Md., USA) were generated from a pool of A7r5 cells by liposomal complex transfection (Effectene; Qiagen Inc., Germany) followed by selection in the presence of geneticin ( $400 \mu \mathrm{g} / \mathrm{ml}$; Invitrogen, Carlsbad, Calif., USA).

\section{Quantitative Real-Time PCR}

Total RNA was extracted from cell pellets or rat carotids (Rneasy; Qiagen), and reverse transcriptase reaction (SuperscriptII, Invitrogen) was performed with $1 \mu \mathrm{g}$ of DNAse I (Amersham Biosciences, Uppsala, Sweden)-treated RNA. Quantitative realtime PCR (qPCR) was carried out using the ABI 7700 thermocycler (Applied Biosystems, Foster City, Calif., USA) and the Quantitect SYBR Green I kit (Qiagen), according to the manufacturers' recommendations. Primer sequences (Invitrogen) were synthesized as follows: gremlin, 5'-CCA GCA GCT GAA GGG AAA AAG AAA-3' (forward) and 5'-TGG CCG TAA CAG AAG CGA TTG A-3' (reverse); GAPDH, 5'-ACC ACA GTC CAT GCC ATC AC-3' (forward) and 5'-TCC ACC ACC CTG TTG CTG TA-3' (reverse); BMP-2, 5'-ACT TCC CGA CGC TTC TTC TTC A-3' (forward) and 5'-GGC CAC TTC CAC CAC AAA CC-3' (reverse); BMP-4, 5'-CCG GCC CCT CCT GGT CAC TTT TG-3' (forward) and $5^{\prime}$-ATC CGC ACC CCT CCA CCA CCA TC-3' (reverse), and BMP-7, 5'-CTG GGC TTC TGA GGA GGG CTG G-3' (forward) and 5'-GCG GTT CTG GCT GCG TTG TTT G-3' (reverse). Polymerase chain reaction was carried out with the following conditions: $1 \mathrm{cycle}$ at $95^{\circ} \mathrm{C}$ for $15 \mathrm{~min}$ and 35 cycles at $94^{\circ} \mathrm{C}(15 \mathrm{~s}), 65^{\circ} \mathrm{C}$ for gremlin, $62^{\circ} \mathrm{C}$ for BMP- 4 and $58^{\circ} \mathrm{C}$ for GAPDH, BMP-2 and BMP-7 (30 s) and $72^{\circ} \mathrm{C} \mathrm{(30} \mathrm{s).} \mathrm{Cycle} \mathrm{numbers} \mathrm{obtained} \mathrm{at} \mathrm{the} \mathrm{log-}$ linear phase of the reaction were plotted against a standard curve prepared with serially diluted control samples. Expression of target genes was normalized to GAPDH mRNA levels measured concurrently. The specificity of each reaction was confirmed by melting curve analysis and agarose gel electrophoresis.

\section{Chromatin Morphology Analysis}

Empty-A7r5 and gremlin-A7r5 at subconfluent stages were deprived of serum for $24 \mathrm{~h}$, after which Hoechst $33342(0.5 \mu \mathrm{g} / \mathrm{ml}$; Molecular Probes Inc., Eugene, Oreg., USA) was added to the medium. Attached and nonattached cells were collected and analyzed under UV fluorescence microscopy $(\times 400)$. Apoptosis was evaluated according to cromatin morphology [17]. Two hundred cells per sample were counted. Results were expressed as the percentage of apoptotic cells.

\section{In vitro Caspase-3 Activity Assay}

Cells were seeded in 6-well plates and cultured until they reached $60-70 \%$ confluence. Cells were made quiescent by incubation with DMEM-F12 0.5\% FBS for $24 \mathrm{~h}$. After that, VSMCs were treated with BMP-2, -4 or $-7(100 \mathrm{ng} / \mathrm{ml})$ for $24 \mathrm{~h}$ in the absence of serum. All cells were collected, washed with PBS and lysed in $200 \mu \mathrm{l}$ of ice-cold $40 \mathrm{mmol} / \mathrm{l}$ Tris- $\mathrm{HCl}$ ( $\mathrm{pH}$ 7.6) with $1 \%$ Triton X-100. Cell extracts were centrifuged and supernatants were collected. Protein extracts $(50 \mu \mathrm{g})$ were diluted in $1 \mathrm{ml}$ of protease assay buffer $(20 \mathrm{mmol} / \mathrm{l} \mathrm{PIPES}, 100 \mathrm{mmol} / \mathrm{l} \mathrm{NaCl}, 10$ $\mathrm{mmol} / \mathrm{lDTT}, 1 \mathrm{mmol} / \mathrm{lEDTA}, 0.1 \%$ CHAPS, $10 \%$ sucrose, $\mathrm{pH}$ 7.2) 
containing $10 \mu \mathrm{l}$ of Ac-DEVD-AFC substrate (Pharmingen, BD Biosciences) and incubated for $1 \mathrm{~h}$ at $37^{\circ} \mathrm{C}$. Samples were analyzed in a fluorimeter (F-2000, Hitachi, Japan) at $505 \mathrm{~nm}$.

\section{Gremlin Gene Silencing}

Lentiviral vectors for gremlin short hairpin (sh) RNA were built with the Block-IT ${ }^{\mathrm{TM}}$ Lentiviral RNAi Expression System (Invitrogen). DNA sequences were designed according to the manufacturer's recommendations and synthesized (Invitrogen) as follows: shGremlin, 5'-CAC CGC ACT ATC ATC AAT CGC TTC TCG AAA GAA GCG ATT GAT GAT AGT GC-3' (sense) and 5'-AAA AGC ACT ATC ATC AAT CGC TTC TTT CGA GAA GCG ATT GAT GAT AGT GC-3' (antisense), and a scrambled control sequence, 5'-CAC CGA CTA CCA TTA CCA TTG CTT CCG AAG AAG CAA TGG TAA TGG TAG TC-3' (sense) and 5'-AAA AGA CTA CCA TTA CCA TTG CTT CTT CGG AAG CAA TGG TAA TGG TAG TC-3' (antisense). These sequences were inserted into pLenti6/Block-IT vectors. To generate lentiviral stocks, $293 \mathrm{FT}$ cells (Invitrogen) were incubated at $37^{\circ} \mathrm{C}$ in a humidified $5 \% \mathrm{CO}_{2} / 95 \% \mathrm{O}_{2}$ atmosphere in DMEM (Invitrogen) containing 4,500 mg/l glucose, supplemented with nonessential amino acids (0.1\%; Invitrogen), L-glutamine ( $6 \mathrm{mmol} / \mathrm{l}$; Invitrogen), sodium pyruvate $(1 \mathrm{mmol} / \mathrm{l}$; Invitrogen), geneticin $(500 \mu \mathrm{g} /$ $\mathrm{ml}$; Invitrogen), $100 \mathrm{U} / \mathrm{ml}$ penicillin, $0.1 \mathrm{mg} / \mathrm{ml}$ streptomycin and $10 \%$ FBS (Invitrogen). Lentiviral stocks were obtained by transfection of $5 \times 10^{6} 293 \mathrm{FT}$ cells with pLenti6/Block-IT-scrambled or pLenti6/Block-IT-shGremlin, along with ViraPower ${ }^{\circledR}$ (Invitrogen) in Opti-MEM-I (Invitrogen) without antibiotics. Cells were cultured for $72 \mathrm{~h}$, and culture medium was collected, centrifuged at $4^{\circ} \mathrm{C}$ and $3,000 \mathrm{rpm}$ for $15 \mathrm{~min}$ and stored at $-80^{\circ} \mathrm{C}$. Lentiviral stocks were titered in A7r 5 cells. For apoptosis, A7r 5 cells and rabbit primary VSMCs were infected with lentivirus-shGremlin or lentivirus-scrambled [moiety of infection (MOI) 5] in DMEMF12 10\% FBS containing $6 \mu \mathrm{g} / \mathrm{ml}$ Polybrene ${ }^{\circledR}$ (Sigma). After $24 \mathrm{~h}$, the medium was changed, and apoptosis was measured $72 \mathrm{~h}$ after infection.

\section{Statistical Analysis}

Comparisons were performed using Student's t test. qPCR values were $\log _{2}$-transformed before the analysis. Results are presented as means \pm SEM. At least 4 different samples were analyzed in each experimental group. $\mathrm{p}<0.05$ was considered significant.

\section{Results}

Gremlin Is Expressed in VSMCs in vivo - Regulation by Injury

Considering gremlin constitutive expression in VSMCs and the potential role of BMPs in vasculopathies, we hypothesized that the modulation of VSMC fate in response to vascular injury involves the regulation of gremlin gene expression. We examined the relative gremlin and BMP-2, -4 and -7 mRNA expression levels in rat carotid arteries after balloon injury. As seen in figure 1, gremlin was markedly downregulated in early stages of

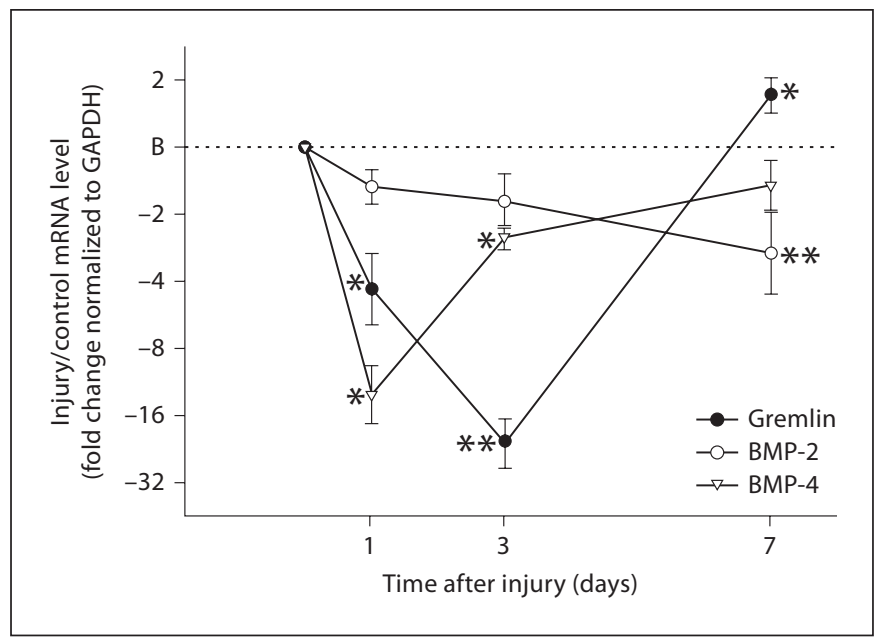

Fig. 1. $\mathrm{qPCR}$ analysis for gremlin, BMP-2 and/or BMP-4 with cDNA obtained from rat carotids following 1, 3 and 7 days of balloon injury. Expression levels were normalized to GAPDH and compared with baseline (B). $\mathrm{n}=4-8 .{ }^{*} \mathrm{p}<0.05,{ }^{* *} \mathrm{p}<0.01$ versus baseline.

the injury. Within the first $24 \mathrm{~h}$, gremlin expression was decreased 4.4-fold ( $\mathrm{n}=4 ; \mathrm{p}<0.05)$, and a maximal 21.5 \pm 3.4 -fold downregulation was observed at day $3(n=8$; $\mathrm{p}<0.001$ ). Gremlin expression returned to original levels by day 7. We confirmed the expression of BMP-2 and BMP- 4 in VSMCs in vitro and in vivo under basal conditions, but not BMP-7 (data not shown). We also examined the expression levels of selected BMPs at identical time points following arterial injury. qPCR analysis revealed significantly decreased BMP- 4 mRNA levels $24 \mathrm{~h}$ after injury (12.9 \pm 1.5 -fold change, $\mathrm{n}=4$; $\mathrm{p}<0.05)$, with its expression returning to baseline at day 7 (fig. 1). A much less intense effect was observed on BMP-2 expression (maximal downregulation at day 7: $3.0 \pm 0.8$-fold, $\mathrm{n}=4$; $\mathrm{p}<0.01$; fig. 1).

\section{Gremlin Expression in VSMCs in vitro - Modulation by Cell Confluence}

The contextual behavior of certain growth factors in vascular biology is well described $[3,7,18]$, with variable effects depending on the level of confluence [19]. In order to determine the pattern of regulation of gremlin expression in vascular injury, we examined mRNA levels of this gene after growth factor administration at different stages of cell confluence. A marked contrast was seen when Ang II, PDGF or TGF- $\beta 1$ were added to pre- or postconfluent VSMC cultures for $3 \mathrm{~h}$ (fig. 2a). Ang II did not modulate gremlin expression at preconfluence, while up- 

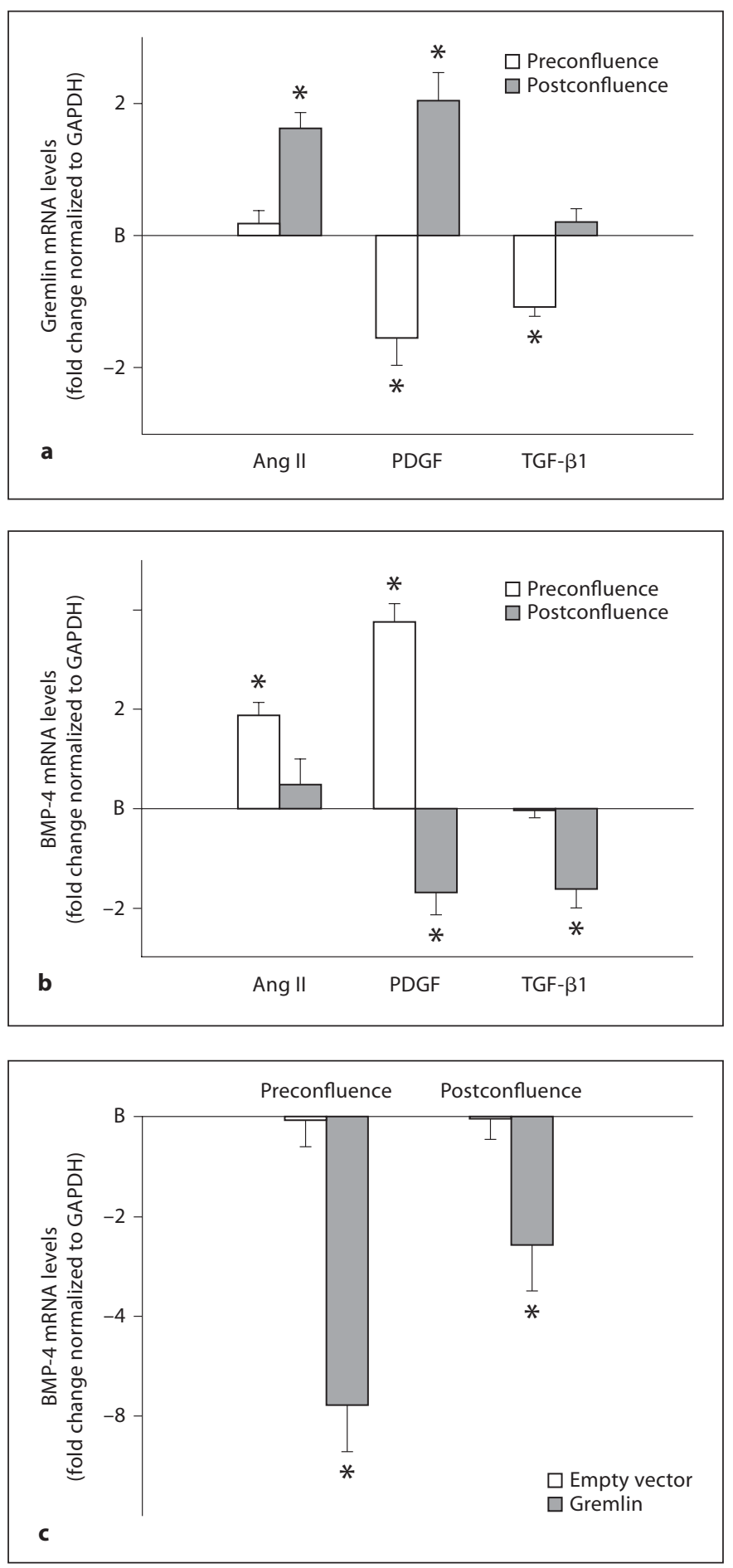

Fig. 2. a, b qPCR analysis for gremlin (a) and BMP-4 (b) with cDNA obtained from aortic smooth muscle cells treated with Ang II (300 nmol/l), TGF- $\beta 1(5 \mathrm{ng} / \mathrm{ml})$ and PDGF $(2 \mathrm{ng} / \mathrm{ml})$ for $3 \mathrm{~h}$, at different confluence stages. c qPCR analysis for BMP-4 with cDNA obtained from empty-A7r5 and gremlin-A7r5 cells, at different confluence stages. Expression levels were normalized to GAPDH and compared with baseline (B). $n=6 .{ }^{*} \mathrm{p}<0.05$ versus baseline. regulation was detected in postconfluent cells $(1.8 \pm 0.1-$ fold change; $p<0.01)$. PDGF produced a bimodal effect, reducing gremlin levels at preconfluence and increasing them at postconfluence $(-1.7 \pm 0.1$ - and $2.0 \pm 0.3$-fold change, respectively; $p<0.01)$. Finally, when TGF- $\beta 1$ was added during preconfluence, gremlin was significantly reduced $(-1.5 \pm 0.1$-fold change; $\mathrm{p}<0.01)$. However, no modification in gremlin mRNA levels was seen in postconfluent VSMC cultures following TGF- $\beta 1$ stimulation. We also evaluated BMP-4 levels under the same circumstances (fig. 2b). Contrary to what was demonstrated for gremlin, BMP-4 levels were upregulated by Ang II and PDGF at preconfluence $(1.9 \pm 0.2-$ and $3.7 \pm 0.5$-fold change, respectively; $\mathrm{p}<0.01)$ and downregulated by PDGF and TGF- $\beta 1$ at postconfluence $(-1.9 \pm 0.1$-fold change in both groups; $p<0.01)$. Finally, we also tested if modifications in gremlin expression would affect BMP-4 levels under a different confluence status. As seen in figure $2 c$, gremlin-overexpressing cells showed a significantly lower expression level of BMP-4 as compared to empty vector-transfected cells. Although significant differences were seen at both stages of cell confluence, it is clear that it predominated in preconfluent cultures $(-7.5$ \pm 0.1 -fold change at preconfluence, $\mathrm{p}<0.01$, and $-2.4 \pm$ 0.1 -fold change at postconfluence, $\mathrm{p}<0.05$ ).

\section{Gremlin Promotes VSMC Apoptosis}

A7r5 cells show reproducible rates of apoptosis when cultured in the absence of serum. Thus, we employed this model to evaluate the potential effects of gremlin on cell death. The absence of mitogenic stimuli for $24 \mathrm{~h}$ induced an increase in apoptosis rates in gremlin-A7r5 (100.0 \pm 4.9 vs. $136.2 \pm 7.3 \%$; $p<0.01$; fig. 3 ) according to cell morphology analysis. In addition, caspase- 3 activity was also significantly increased in gremlin-A7r5 as compared to empty-A7r5 following serum removal (100.0 $\pm 6.5 \mathrm{vs.}$ $165.7 \pm 9.5 \%, \mathrm{n}=8 ; \mathrm{p}<0.001$; fig. 3).

\section{Exogenous BMP Administration Produces Only \\ Partial Antagonism of Gremlin-Induced VSMC Apoptosis}

We anticipated that the effects of gremlin on VSMCs would be secondary to functional antagonism of BMP signaling. Thus, we treated transfected A7r5 cells with BMP-2, -4 or -7 , and caspase- 3 activity was measured. In control cells, all BMPs tested markedly inhibited serum starvation-induced death (fig. 4). Similarly, when BMPs were added on top of gremlin overexpression, the caspase-3 activity detected was significantly lower (fig. 4). However, the magnitude of the inhibitory effect of the 


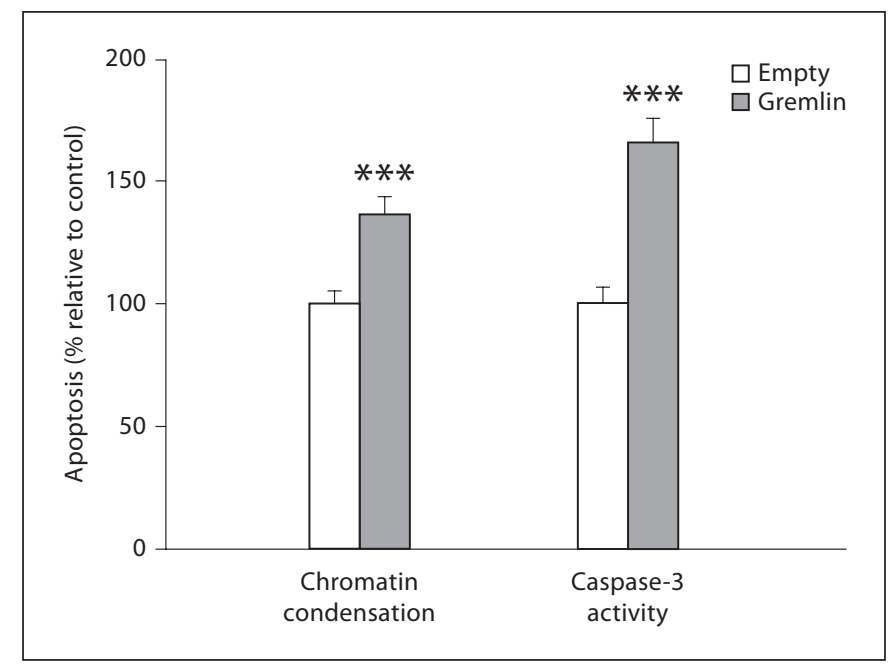

Fig. 3. Empty-A7r5 and gremlin-A7r5 were deprived of serum for $24 \mathrm{~h}$, and cell apoptosis was quantitated by nuclear chromatin morphology and caspase- 3 activity. $\mathrm{n}=8-9$. ${ }^{* * *} \mathrm{p}<0.001$.

BMPs (18-26\%) was smaller when compared to that observed in empty vector-transfected cells (41-54\%), suggesting that other mechanisms act on gremlin-induced VSMC apoptosis.

\section{Gremlin Gene Silencing Reduces VSMC Apoptosis}

Initially, we confirmed the effectiveness of our gremlin gene silencing strategy in A7r5 cells (fig. 5a). At MOI 5 , we obtained satisfactory inhibition of gremlin expression with minimal immediate cell loss due to infection toxicity (data not shown). Gremlin shRNA infection promoted a significant inhibition of VSMC apoptosis when chromatin condensation (100 $\pm 4 \%$ for scrambled-A7r5 vs. $84 \pm 6 \%$ for shGremlin-A7r5, $\mathrm{n}=4$; $\mathrm{p}<0.05$; fig. $5 \mathrm{c})$ and caspase- 3 activity were evaluated $(100 \pm 3 \%$ for scrambled-A7r5 vs. $79 \pm 4 \%$ for shGremlin-A7r5, $\mathrm{n}=4$; $\mathrm{p}<0.01$; fig. 5c). In order to confirm data obtained with A7r 5 cells, we also analyzed the effects of gremlin downregulation on rabbit primary VSMCs. Although the rabbit gremlin gene sequence is not available in public databases, we were able to identify gremlin mRNA in rabbit VSMCs using the same set of primers utilized for rat cells (data not shown). Next, we demonstrated that, as witnessed for A7r5 cells, the shRNA strategy significantly reduced gremlin expression levels (fig. 5b). We were able to demonstrate that inhibition of gremlin expression effectively reduced serum withdrawal-induced apoptosis, according both to chromatin morphology analysis (100 $\pm 5 \%$ for scrambled-A7r5 vs. $81 \pm 3 \%$ for shGremlin-

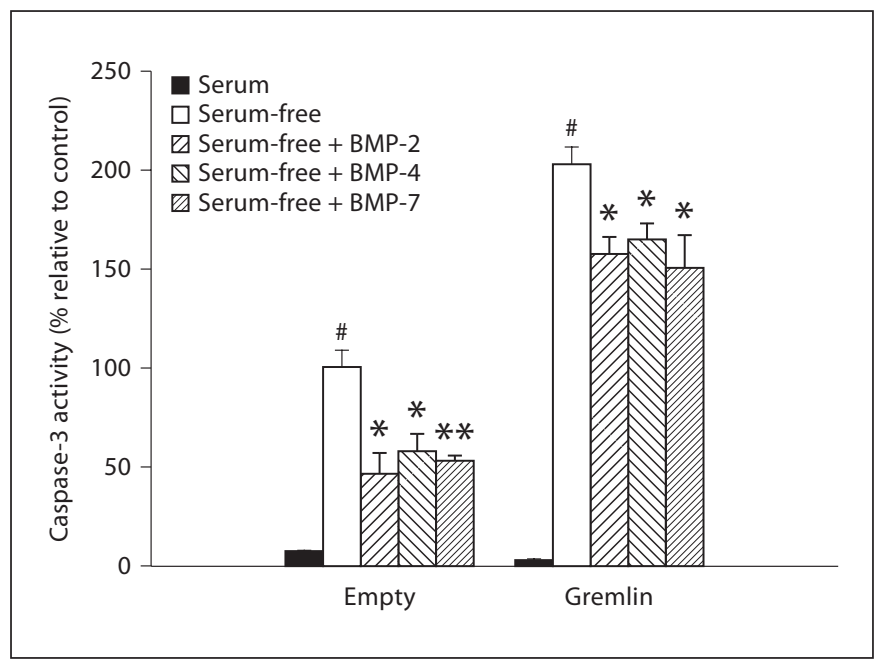

Fig. 4. Empty-A7r5 and gremlin-A7r5 were cultured in the presence or absence of serum, and caspase-3 activity was evaluated following the administration of BMP-2, BMP-4 and BMP-7 (100 $\mathrm{ng} / \mathrm{ml}$ ) or vehicle. $\mathrm{n}=6 .{ }^{*} \mathrm{p}<0.05,{ }^{* *} \mathrm{p}<0.01$ versus serum-free; ${ }^{\#} \mathrm{p}<0.05$ versus serum-free empty-A7r5.

A7r5, $\mathrm{n}=6$; $\mathrm{p}<0.05$; fig. $5 \mathrm{~d})$ and caspase-3 activity (100 $\pm 4 \%$ for scrambled-A7r 5 vs. $67 \pm 3 \%$ for shGremlin$\mathrm{A} 7 \mathrm{r} 5, \mathrm{n}=6$; $\mathrm{p}<0.05$; fig. $5 \mathrm{~d}$ ).

\section{Discussion}

VSMC apoptosis is of relevance in the early stages of vascular injury [6]. Recently, Matter et al. [20] demonstrated that FasL knockout mice present higher levels of neoitimal hyperplasia, suggesting that apoptosis may have an active role during the development of neointima. In our experiments, chromatin condensation and caspase- 3 activity were significantly increased in gremlinoverexpressing A7r5 cells. If we consider that gremlin gene expression is reduced during the first days of vascular injury, our data suggest a possible mechanism of apoptosis resistance during neointimal development. In addition, gremlin gene silencing significantly suppressed apoptosis in A7r5 and rabbit primary VSMCs as well, indicating that gremlin participates in the control of VSMC apoptosis also under basal conditions. We speculate that downregulation of gremlin mRNA in vivo decreases apoptosis and, consequently, potentiates neointimal hyperplasia. This antiapoptotic mechanism may partially compensate marked reductions in BMP levels (particularly BMP-4) accompanying gremlin downregulation. 


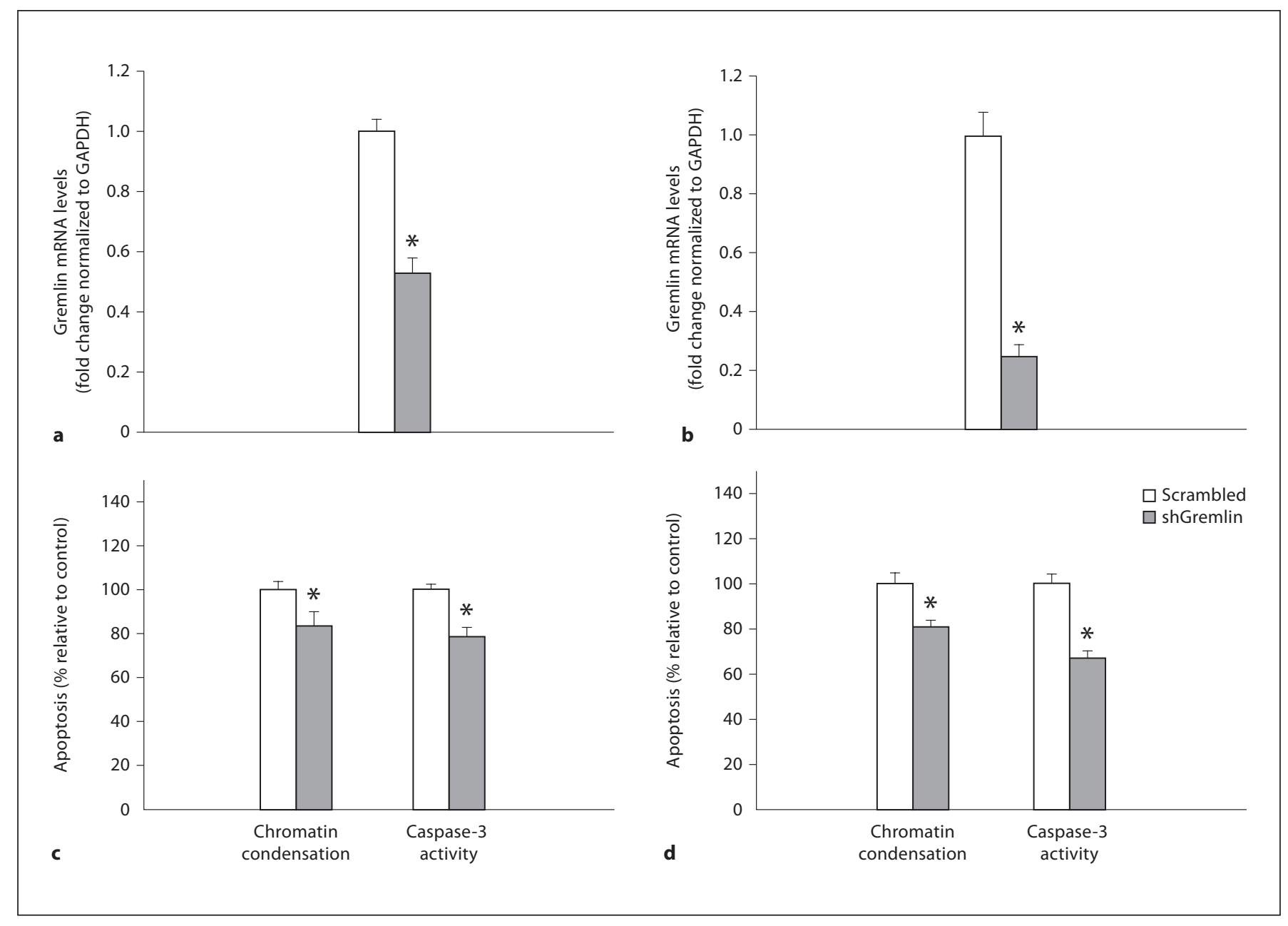

Fig. 5. a, b qPCR analysis for gremlin with cDNA obtained from A7r5 cells (a) and rabbit primary VSMCs (b) infected with scrambled or shGremlin lentivirus for $72 \mathrm{~h} . \mathrm{n}=4 .{ }^{*} \mathrm{p}<0.05$ versus scrambled. Expression levels were normalized to GAPDH. c, d A7r5 cells (c) and rabbit VSMCs (d) were infected with scrambled or shGremlin lentivirus at MOI 5 and deprived of serum for $24 \mathrm{~h}$, and cell apoptosis was quantitated by nuclear chromatin morphology and caspase- 3 activity. $\mathrm{n}=4-6 .{ }^{*} \mathrm{p}<0.05$ versus scrambled.

During the course of neointimal development, VSMCs move from a situation of preconfluence (immediately after balloon injury and during intense medial-layer VSMC death) to a postconfluent stage, when neointima is already formed $[3,6,18-21]$. As we have seen, gremlin expression in response to growth factor stimulation is also dependent on cell confluence status. Of interest, gremlin was downregulated in vitro by PDGF when cells were subconfluent. In the early stages of vascular lesion formation, PDGF, a known antiapoptotic growth factor, is increased within the vessel wall [22]. Gremlin was markedly downregulated at the same time points in our in vivo experiments. Data from other groups show that TGF- $\beta 1$ is increased after vascular injury [23], playing a role in neointimal formation through VSMC phenotype modification and extracellular matrix accumulation [24]. It is of relevance that TGF- $\beta 1$ also protects VSMCs from apoptosis in vitro [25]. As seen for PDGF, TGF- $\beta 1$ reduced gremlin expression at preconfluence, suggesting that this cytokine would contribute, in part, to gremlin downregulation in vivo. Finally, although Ang II increased gremlin levels during postconfluence, no effect was seen at preconfluent stages, indicating that VSMC apoptosis resistance conferred by Ang II [17] does not involve gremlin downregulation. At the same time, a coordinated regulation of BMP-4 in an opposite direction to 
that seen for gremlin was induced by all growth factors tested. It is also relevant that gremlin negatively affects the expression of BMP-4, particularly in subconfluence. Taken together, these results demonstrate that the regulation of gremlin and BMP-4 expression is dependent on cell confluence status and suggest a contextual role of gremlin in vascular injury.

The dual time- and confluence-dependent role of gremlin in neointima formation (apoptosis vs. induction of cell proliferation and migration) suggests that strategies aimed at preventing post-percutaneous transluminal coronary angioplasty restenosis should consider more complex scenarios than simply addressing specific targets at a single time point. In recent years, different approaches were demonstrated to be effective in modulating VSMC phenotype in vitro and reducing neointima accumulation in animal models. However, when tested in other species (including humans), they were not significantly effective [26, 27]. Such phenomena are assumed to be a consequence of the existence of distinct mechanisms responsible for restenosis. The elimination of one particular pathway would be compensated by several others. Nevertheless, our results indicate that the timing of the intervention appears to be also of the essence. It is conceivable to assume, for instance, that gremlin blockade would reduce neointima formation if initiated at later time points following a vascular intervention. However, lesion formation could actually be potentiated if gremlin inhibition was to be started right after the angioplasty.

Analysis of the role of BMPs in apoptosis is controversial and intimately related to the cell type or tissue studied. BMP-2 induces apoptosis of pulmonary artery smooth muscle cells [28]. In our studies, serum depriva- tion-induced apoptosis was significantly reduced after the administration of BMP to empty-A7r5 cells. This effect was much less pronounced in gremlin-overexpressing cells, indicating additional mechanisms involved in gremlin-induced apoptosis. In fact, experiments with vascular BMP gain of function reduced neointima formation [8], indicating that the antiproliferative effects of BMPs may be more relevant than their antiapoptotic properties. We are concentrating our efforts now on identifying additional pathways modified by gremlin. We hope to be able to individualize BMP antagonism-dependent and -independent effects of gremlin in the vasculature.

BMP signaling has recently emerged as an essential factor in vascular physiopathology and functioning of VSMCs [8, 10, 29-32]. Our data reinforce this notion, especially if we consider the magnitude of BMP and gremlin regulation observed in vivo and the significant modulation of cell death promoted by gremlin overexpression in vitro. These results, combined with previous data from our laboratory, demonstrate an important role of gremlin in VSMC phenotype modulation, including cell proliferation, migration and apoptosis. Our findings suggest that a better comprehension of the function of gremlin (and the BMP pathway as a whole) in the vasculature will bring significant contributions to the field of vascular biology.

\section{Acknowledgements}

This work was supported by the Fundação de Amparo à Pesquisa do Estado de São Paulo, grant number 06/00456-0, and the Albert Einstein Research and Education Institute.

\section{References}

1 Perlman H, Maillard L, Krasinski K, Walsh $\mathrm{K}$ : Evidence for the rapid onset of apoptosis in medial smooth muscle cells after balloon injury. Circulation 1997;95:981-987.

2 Ross R: The pathogenesis of atherosclerosis: a perspective for the 1990s. Nature 1993;362: 801-809.

3 Schwartz SM, Majesky MW, Murry CE: The intima: development and monoclonal responses to injury. Atherosclerosis 1995; 118(suppl):S125-S140.

4 Gibbons GH, Dzau VJ: The emerging concept of vascular remodeling. N Engl J Med 1994;330:1431-1438.
5 Han DK, Haudenschild CC, Hong MK, Tinkle BT, Leon MB, Liau G: Evidence for apoptosis in human atherogenesis and in a rat vascular injury model. Am J Pathol 1995; 147: $267-277$

6 Pollman MJ, Hall JL, Gibbons GH: Determinants of vascular smooth muscle cell apoptosis after balloon angioplasty injury. Influence of redox state and cell phenotype. Circ Res 1999;84:113-121.

7 Schwartz SM, deBlois D, O'Brien ER: The intima. Soil for atherosclerosis and restenosis. Circ Res 1995;77:445-465.
8 Nakaoka T, Gonda K, Ogita T, OtawaraHamamoto Y, Okabe F, Kira Y, Harii K, Miyazono K, Takuwa Y, Fujita T: Inhibition of rat vascular smooth muscle proliferation in vitro and in vivo by bone morphogenetic protein-2. J Clin Invest 1997;100:28242832

9 Ducy P, Karsenty G: The family of bone morphogenetic proteins. Kidney Int 2000;57: 2207-2214.

10 Bostrom K, Watson KE, Horn S, Wortham C, Herman IM, Demer LL: Bone morphogenetic protein expression in human atherosclerotic lesions. J Clin Invest 1993;91:18001809 . 
11 Hruska KA, Mathew S, Saab G: Bone morphogenetic proteins in vascular calcification. Circ Res 2005;97:105-114.

-12 Derynck R, Zhang YE: Smad-dependent and Smad-independent pathways in TGF-beta family signalling. Nature 2003;425:577584.

13 Balemans W, Van Hul W: Extracellular regulation of BMP signaling in vertebrates: a cocktail of modulators. Dev Biol 2002;250: 231-250.

- 14 Hsu DR, Economides AN, Wang X, Eimon PM, Harland RM: The Xenopus dorsalizing factor Gremlin identifies a novel family of secreted proteins that antagonize BMP activities. Mol Cell 1998;1:673-683.

-15 Maciel TT, Melo RS, Schor N, Campos AH: Gremlin promotes vascular smooth muscle cell proliferation and migration. J Mol Cell Cardiol 2008;44:370-379.

-16 Morishita R, Gibbons GH, Ellison KE, Nakajima M, Zhang L, Kaneda Y, Ogihara T, Dzau VJ: Single intraluminal delivery of antisense cdc2 kinase and proliferating-cell nuclear antigen oligonucleotides results in chronic inhibition of neointimal hyperplasia. Proc Natl Acad Sci USA 1993;90:8474-8478.

- 17 Pollman MJ, Yamada T, Horiuchi M, Gibbons GH: Vasoactive substances regulate vascular smooth muscle cell apoptosis: countervailing influences of nitric oxide and angiotensin II. Circ Res 1996;79:748-756.

$\checkmark 18$ Schwartz SM: The intima: a new soil. Circ Res 1999;85:877-879.
19 Li XA, Bianchi C, Sellke FW: Rat aortic smooth muscle cell density affects activation of MAP kinase and Akt by menadione and PDGF homodimer BB. J Surg Res 2001;100: 197-204.

20 Matter CM, Chadjichristos CE, Meier P, von Lukowicz T, Lohmann C, Schuler PK, Zhang D, Odermatt B, Hofmann E, Brunner T, Kwak BR, Luscher TF: Role of endogenous Fas (CD95/Apo-1) ligand in balloon-induced apoptosis, inflammation, and neointima formation. Circulation 2006;113:1879-1887.

21 Carter AJ, Laird JR, Farb A, Kufs W, Wortham DC, Virmani R: Morphologic characteristics of lesion formation and time course of smooth muscle cell proliferation in a porcine proliferative restenosis model. J Am Coll Cardiol 1994;24:1398-1405

-22 Ferns GA, Raines EW, Sprugel KH, Motani AS, Reidy MA, Ross R: Inhibition of neointimal smooth muscle accumulation after angioplasty by an antibody to PDGF. Science 1991;253:1129-1132.

23 Majesky MW, Lindner V, Twardzik DR, Schwartz SM, Reidy MA: Production of transforming growth factor beta 1 during repair of arterial injury. J Clin Invest 1991;88: 904-910.

24 Bobik A: Transforming growth factor-betas and vascular disorders. Arterioscler Thromb Vasc Biol 2006;26:1712-1720.

25 Pollman MJ, Naumovski L, Gibbons GH: Vascular cell apoptosis: cell type-specific modulation by transforming growth factorbetal in endothelial cells versus smooth muscle cells. Circulation 1999;99:20192026.

-26 Wilensky RL: Angiotensin-receptor blockers: revival of the systemic prevention of restenosis? Cardiovasc Drugs Ther 2003;17: 63-73.
$>27$

W, Heyndrickx GR, Patel J, Cummins PA, Kleijne JA, Clowes AW: Effect of an anti-PDGF-beta-receptor-blocking antibody on restenosis in patients undergoing elective stent placement. Int J Cardiovasc Intervent 2003;5:214-222.

28 Zhang S, Fantozzi I, Tigno DD, Yi ES, Platoshyn O, Thistlethwaite PA, Kriett JM, Yung G, Rubin LJ, Yuan JX: Bone morphogenetic proteins induce apoptosis in human pulmonary vascular smooth muscle cells. Am J Physiol Lung Cell Mol Physiol 2003; 285:L740-L754.

29 Willette RN, Gu JL, Lysko PG, Anderson KM, Minehart H, Yue T: BMP-2 gene expression and effects on human vascular smooth muscle cells. J Vasc Res 1999;36:120-125.

30 Dorai H, Vukicevic S, Sampath TK: Bone morphogenetic protein-7 (osteogenic protein-1) inhibits smooth muscle cell proliferation and stimulates the expression of markers that are characteristic of SMC phenotype in vitro. J Cell Physiol 2000;184:37-45.

31 Hsieh PC, Kenagy RD, Mulvihill ER, Jeanette JP, Wang X, Chang CM, Yao Z, Ruzzo WL, Justice S, Hudkins KL, Alpers CE, Berceli S, Clowes AW: Bone morphogenetic protein 4: potential regulator of shear stress-induced graft neointimal atrophy. J Vasc Surg 2006;43:150-158.

>32 Corriere MA, Rogers CM, Eliason JL, Faulk J, Kume T, Hogan BL, Guzman RJ: Endothelial Bmp4 is induced during arterial remodeling: effects on smooth muscle cell migration and proliferation. J Surg Res 2008;145: 142-149. 